\title{
Discussão sobre o Business Intelligence em empresas de Tecnologia da Informação
}

\author{
Mauro Maia Laruccia', Regiani Salvático Pereira da Silva², Gabriella \\ Dottavio Chiarelli²
}

Recebido em: 05/06/2013. Aprovado em: 22/06/2013. Disponibilizado em: 24/06/2013

1. Bacharel em Administração de Empresas pela Pontifícia Universidade Católica de São Paulo (1983), mestre em Administração pela Pontifícia Universidade Católica de São Paulo (1997) e Doutor em Comunicação e Semiótica pela Pontifícia Universidade Católica de São Paulo (2002). Atualmente é professor do Programa de Mestrado em Semiótica, Tecnologias da Informação e Educação da Universidade Braz Cubas, com pesquisa apoiada pela FAPESP, Professor da FEA/PUCSP, professor do Pós-graducão da FAAP e das Faculdades Integradas Campos Salles. Avaliador Ad Hoc do INEP/MEC. E-mail: mauro.laruccia@gmail.com

2. FEA da Pontifícia Universidade Católica de São Paulo.

\section{Resumo}

O objetivo geral é identificar como o Business Intelligence pode ajudar uma empresa na área de tecnologia da informação. O problema é baseado em BI e como sua utilização pode trazer benefícios para as empresas que o utilizam. Essas estão constantemente procurando a inteligência empresarial, por ser um método inovador de auxílio na tomada de decisões. Basicamente, este artigo está focado em empresas de tecnologia da informação, apesar de existir empresas de empresas de diversos setores que utilizam essa solução. $\mathrm{O}$ artigo conclui que o uso da ferramenta Business Intelligence vem crescendo assustadoramente conforme é empregado nas organizações.

Palavras-chave: Business Intelligence; tecnologia da informação; tomada de decisões.

\begin{abstract}
The overall objective is to determine how Business Intelligence can help a company in the field of information technology. The problem based on BI and how their use can bring benefits to companies that use it. These are constantly looking for business intelligence, for being an innovative method of funding in the decisionmaking. Basically, this article focuses on information technology companies, despite the survival of companies from different sectors that use this solution. The article concludes that the use of Business Intelligence tool is growing alarmingly as used in organizations.
\end{abstract}

Keywords: Business Intelligence, information technology, decision-making. 



\section{Introdução}

O termo Business Intelligence surgiu como uma inovação na década de 70 do século passado. Nessa época, utilizava-se a programação linear como base para seu uso, o que encarecia muito seu custo. Com o intenso avanço tecnológico e o surgimento de meios facilitadores como: banco de dados e computadores pessoais fez com que pesquisadores começassem a desenvolver soluções eficazes para organizar todas as informações que estavam surgindo nesse período.

Atualmente, as soluções em BI são inúmeras visto que sua variedade está em constante crescimento e atualização. Essa expansão deve-se ao fato de um número cada vez maior de empresas estar interessada nessa ferramenta.

Segundo Sabherwal e BecerraFernandez (2009), BI é definido como:

We define business intelligence (BI) as providing makers with valuable information and knowledge by leveraging a variety of sources of data as well as structured and unstructured information. The information and data could reside within or outside the organization, could be obtained from multiple sources, could be structured in different ways, and could be either quantitative or qualitative (p.6).

Uma empresa da área de tecnologia da informação armazena, distribui e compartilha diariamente inúmeras informações que necessitam ser armazenadas e utilizadas como meio de tomada decisão. Por esse motivo, a ferramenta BI torna-se uma interessante alternativa para auxiliar a organização de dados.

O objetivo geral é identificar o quanto e como o Business Intelligence pode ajudar uma empresa na área de tecnologia da informação com suas soluções.

Os objetivos específicos são: (1) fazer um levantamento de prós e contras da utilização de BI; (2) identificar soluções que possam ser alcançadas com o uso; (3) identificar possíveis vantagens em relação o mercado das empresas que utilizam BI; (4) identificar como o resultado da utilização da ferramenta impacta nas decisões de uma empresa de TI; e (5) fazer uma relação entre as contas estratégicas da empresa e a utilização de BI.

O problema dessa pesquisa objetivará, genericamente, esclarecer como o uso do capital intelectual pode impactar no sucesso de uma organização da área de tecnologia. Ou seja, como o uso especificamente do BI pode impactar e influenciar no desempenho da empresa diante o mercado e suas singularidades.

O problema define-se em mensurar o uso da inteligência empresarial no âmbito tanto interno, estipulando melhorias e avanços nos processos decisórios quanto externos, avaliando o impacto no mercado. A gestão das informações de uma empresa é, com certeza, um ponto de atenção como expressa a citação a seguir.

Segundo Fabio Vinicius Primak (2008)

É indiscutível a relevância da disponibilidade das informações apropriadas para o administrador no processo decisório, principalmente no momento da tomada da decisão. Sem ela, o administrador decidirá às cegas. Essa mesma informação servirá como instrumento de avaliação da qualidade da decisão, tomada por meio da alimentação de um processo de feedback (p.14).

Conforme apontado acima, é de suma importância os gestores das organizações terem know how das informações que 
circulam e estão armazenadas na empresa, porque é a partir delas que decisões e previsões poderão ser tomadas.

\section{O Business Intelligence e a Tomada de Decisão}

Business Intelligence, ou Inteligência Empresarial, refere-se ao processo de coleta, exploração, organização, análise, compartilhamento e monitoramento de informações que oferecem suporte à gestão dos negócios e permitem incrementar a tomada de decisão. Sendo assim, é um método que ajuda as empresas a tomarem decisões inteligentes, diante da coleta de dados e da transformação deles em informações valiosas para a melhoria constante de seus negócios.

Diante do mundo globalizado, as informações crescem e circulam de maneira muito rápida e a demanda por informações de qualidade acompanham este mesmo ritmo. O importante neste cenário é saber reter as informações que são relevantes e que vão subsidiar todas as tomadas de decisões.

Quando uma empresa pensa em desenvolver um programa de BI, ela deve determinar quais são as necessidades de curto e médio prazo da empresa. Para a eficiente implementação deste método, é fundamental que se tenha em mente quais são as suas verdadeiras necessidades.

Com relação às metas e os objetivos que a empresa deseja atingir, é muito importante que os objetivos e metas sejam claros e definidos para que se colete e sejam analisadas as informações corretas, sem que haja perda de tempo e dinheiro.

Além disso, é importante que haja o alinhamento do planejamento estratégico. Cada vez mais, há um distanciamento entre a visão estratégica dos executivos e o resto da empresa, pois a estratégia é mal repassada. $\mathrm{O}$ BI tende a eliminar essa situação.

É necessário ter em mente os custos e os riscos, ou seja, quais serão as conseqüências financeiras da utilização do processo, desde o valor que a empresa está disposta a pagar até os riscos que ela está disposta a correr.

Os stakeholders são os beneficiados com o programa. Por isso, devem ser identificados e analisados com muita atenção.

Como e quem irá monitorar as informações é importante para que elas tenham relevância e validade. É preciso criar um grupo com conhecimento interno capaz de deter, filtrar e analisar as informações que devem ser operacionalizadas.

O profissional responsável pela coleta de dados, precisa da colaboração das demais áreas do negócio para que haja comprometimento de todos na hora de passar as informações. Caso contrário, o BI não atenderá as necessidades reais da empresa.

A melhor estratégia de ação deve ser definida. Com todas as informações recolhidas e processadas, deve-se decidir qual será a estratégia usada para que a empresa saia na frente de seus concorrentes e atinja com eficácia os seus objetivos.

Em linhas gerais, a utilização do BI contém três passos importantes: coletar dados, gerar informações e tomar decisões.

Para se coletar dados, é necessários buscá-los dentro da própria empresa e, também, fora dela. Com os dados em mãos, é necessário analisá-los com cuidado para gerar as informações relevantes. Finalmente, com as informações estruturadas, é possível tomar as decisões certas e no tempo certo. 
Analisar o ambiente é transformar as ameaças em oportunidades, fazendo com que os fatores que influenciam as decisões de uma empresa sejam positivos para os resultados finais.

Os sistemas de informações têm um papel fundamental neste cenário e prestam grande contribuição, pois fornecem as ferramentas necessárias para extrair, guardar e explorar dados e conseqüentemente, aprimorar o processo da tomada de decisão. (2003):

De acordo com Angelo Palmisano

Um sistema de informação pode ser definido como os procedimentos, os métodos, a organização, os elementos de software e hardware necessários para inserir e recuperar dados selecionados conforme forem sendo exigidos para a operação e a gestão de uma empresa.

Pessoas envolvidas no processo de BI utilizam softwares e outras tecnologias para facilitar o acesso aos dados e melhorar o desempenho de gerenciamento do negócio

Gerenciar uma empresa é um desafio muito grande para todo aquele indivíduo que possui uma posição estratégica e que busca detectar tendências e tomar decisões corretas e eficientes no tempo certo. Por isso, as empresas implementam sistemas de BI e os incorporam aos projetos para otimização dos processos. Através da análise de dados contextualizados, é possível atingir esse objetivo de forma mais rápida e precisa.

Com o BI, ocorre a democratização das informações. As primeiras fontes de informações que são analisadas se encontram dentro da própria empresa. Cada fonte ajuda aqueles que precisam entender o negócio e tomar a decisão mais correta possível. As outras fontes se encontram no ambiente externo, ou seja, tudo o que influencia o modo de agir da empresa e que não está dentro dela. As informações do ambiente externo podem ser as necessidades dos clientes, a concorrência, os aspectos econômicos, culturais e sociais. Pesquisas de marketing, de mercado e análises competitivas, completam a base de informações.

Para que haja eficiência nos negócios, essas informações precisam estar disponíveis de forma clara e rápida, os usuários saibam usá-las e que seja usado o melhor método para extraí-las, de forma que o BI realmente se torne um sistema de apoio às decisões.

De acordo com Fábio Vinícius Primark: (2008)

Nos dias atuais, corporações de pequeno, médio e grande porte necessitam do BI para auxiliá-las nas mais diferentes situações para a tomada de decisão, otimizar o trabalho, reduzir custos, eliminar a duplicação de tarefas, permitir previsões de crescimento da empresa como um todo e contribuir para a elaboração de estratégia.

O BI pode ser aplicado em qualquer empresa, pois todas precisam ser gerenciadas, necessitam de indicadores de desempenho e informações internas e externas para a tomada de decisões. O uso do BI traz muitas vantagens, pois permite a inovação, melhora o desempenho da empresa, tem-se a noção dos riscos ou desvios do que foi planejado, tem-se o melhor conhecimento da realidade, pode-se detectar fraudes e ter acesso a informações de qualidade.

As organizações buscam a inteligência empresarial para aumentar os seus diferencias competitivos, levando em conta a tomada de decisões. Dentro do BI, a informação é um elemento estratégico para as organizações se destacarem e terem um maior reconhecimento no mercado a cada dia que passa. 
O BI é um sistema de mecanismos que fazem chegar a informação certa, para as pessoas certas e no momento certo. O mercado de Inteligência Empresarial conta com muitas soluções e ferramentas para auxiliarem na tomada de decisão. Porém, todas precisam ser muito bem analisadas e alinhadas, verificando os prós e os contras.

\section{As Empresas de Teconologia da Informação e o Impacto na Vantagem Competitiva}

O BI, se utilizado corretamente, traz muitos benefícios para a empresa que o adota. Com ele é possível usar a inteligência em todos os processos, sem que haja desperdícios e resultados inesperados.

Esse método proporciona o objetivo principal de qualquer empresa: o lucro. Este é obtido através da satisfação das necessidades dos clientes e da fidelização dos mesmos, da maior produção de bens e da alocação correta dos recursos disponíveis. Deste modo, gerando economia e possível maximizar os lucros e sair na frente da concorrência. Com o BI, as informações são obtidas rapidamente e de forma estruturada, fazendo com que a empresa conheça os seus pontos fortes e fracos, podendo corrigi-los com mais rapidez. Além disso, é possível ter um rápido retorno sobre a satisfação dos clientes e definir novas estratégias para se expandir no mercado.

$\mathrm{O}$ BI engloba diversos processos que darão o suporte e firmeza para as decisões em diversas áreas do negocio. Esses são os motivos que levam o BI a ser um grande diferencial competitivo.

Nos dias de hoje as organizações contam com um mercado grande de produtos na área de inteligência competitiva. Existem empresas no mercado especializadas em soluções de BI que permitem as organizações alinharem sua estratégia de negócio à sua execução utilizando como ponte a Tecnologia da Informação. Dentre elas, podemos citar a Microsoft que, aproveitando do crescimento de mercado de BI, criou uma base completa para ajudar a tecnologia da informação a impulsionar o BI por toda a organização e oferecer inteligência onde os usuários precisam.

As organizações que estão atrás de inteligência empresarial investem no processo de busca de informações com o objetivo de aumentar seus diferenciais competitivos, levando-as a ter uma tomada de decisão com propriedade e base para mesma. Este processo de busca da informação deve iniciar-se dentro da própria organização e também pode ser ajudado com pesquisas de marketing, mercado, negócio e concorrência.

Algumas ferramentas são imprescindíveis na estrutura tecnológica do BI. Alguns exemplos são: (1) ETL (análise e desenvolvimento de relatórios), (2) Data Warehouse ou Data Mart (repositórios de dados), (3) OLAP (análise dinâmica dos dados).

Essas ferramentas são criadas por empresas de tecnologia da informação, que têm o objetivo de criar soluções para seus clientes, dentro do BI. Exemplos dessas empresas são Oracle, SAS, SAP, IBM entre outras.

De acordo com O’Brien (2004):

Dessa forma, os sistemas de informação devem ser projetados para produzir uma multiplicidade de produtos de informação para atender as necessidades variáveis dos tomadores de decisão na organização como um todo. (...) Portanto, fornecer informações e apoio para todos os 
níveis da tomada de decisão gerencial não é tarefa fácil. (O’BRIEN, 2004, p.250)

Utilizando o BI, elas criam programas tecnológicos que proporcionam o cliente inovar, aproveitar as oportunidades e transformá-las em fatores de sucesso, facilitando suas ações na hora da tomada de decisão, ou seja, as empresas de tecnologia utilizam o BI para fornecerem suporte ao próprio BI de outras empresas. Por isso, as empresas de tecnologia da informação são peças chaves no processo de BI. Elas fornecem para as empresas as ferramentas certas e necessárias para coletar dados, analisar e agir de forma correta, além de reconhecer clientes potencias e se impor diante da concorrência. $\mathrm{O}$ uso adequado dessas ferramentas certamente fazem as empresas terem vantagem competitiva no mercado.

\section{Considerações Finais}

Com o presente artigo pode-se concluir que o uso da ferramenta Business Intelligence vem crescendo assustadoramente conforme é empregado nas organizações. Isso acontece, pois grande parte das organizações possui inúmeros dados e informações aleatórias e sem relações.

O BI possibilita a realização de uma série de análises e projeções, agilizando os processos relacionados às tomadas de decisão e ainda proporciona certa vantagem no meio corporativo em relação aos concorrentes.

Com a globalização, a competição está cada vez mais acirrada e as informações assumem um papel fundamental nessa corrida para ser a melhor. Com a utilização do BI, a empresa sairá na frente, descobrindo os problemas com seus produtos, possibilitando corrigi-los com maior velocidade, ainda irá saber se seus clientes estão satisfeitos e poderá definir novas estratégias para expansão no mercado. Portanto, com uma economia veloz, essas tecnologias são um grande diferencial competitivo.

É de suma importância que os benefícios que se tem com a utilização do BI estejam sempre alinhados aos compromissos e interesses de cada empresa e direcionados às metas previamente estabelecidas. Trabalhar o conhecimento usando o BI precisa estar sempre bem alinhado às definições dos processos evolutivos da empresa em conjunto com novas práticas comerciais. Nessas, em melhores maneiras de relacionamento com os clientes e em novas formas de sobrevivência visando sempre usar a inteligência nas tomadas de decisão precisas e coerentes.

É necessário também que a empresa saiba nortear o seu capital intelectual para que dessa forma as informações propiciadas pelo $\mathrm{BI}$ atendam às expectativas esperadas.

A fácil visualização dos dados, integração com vários locais de informação formam o verdadeiro capital intelectual e completo da empresa, trazendo conhecimento para as decisões imediatas e para aquelas que virão no futuro.

Atualmente, as organizações podem contar com um mercado amplo de produtos na área de inteligência empresarial. Existem empresas no mercado especializadas em soluções de BI, dentre elas podemos citar: Oracle, SAS, SAP, IBM entre outras.

Para finalizar, devemos reconhecer que desenvolver o BI, bem como instituir metas e métricas de informação, pode ser uma experiência desafiadora para uma empresa, mas certamente será um apoio inestimável para aquelas que buscam alavancar seus negócios e tornarem-se mais competitivas.

\section{Bibliografia}


1. BUSINESS INTELLIGENCE BLOG. Has BI Become a Commodity? Disponível em: <http://www.businessintelligence.com/ blog/has-bi-become-a-commodity>. Acesso em: 22 out. 2011.

2. CHING SENG YAP; RASHID, M. Z. A. Acquisition and strategic use of competitive intelligence. Malaysian Journal of Library \& Information Science, v. 16, n. 1, p. 125-136, jul 2011.

3. GESSNER, G.; SCOT'T, R. A. Using Business Intelligence Tools to Help Manage Costs and Effectiveness of Business-toBusiness Inside-Sales Programs. Information Systems Management, v. 26, p. 199-208, 14 abr 2009.

4. KOCAKOÇ, I. D.; ERDEM, S. Business Intelligence Applications in Retail Business: OLAP, Data Mining \& Reporting Services. Journal of Information \& Knowledge Management, v. 09, p. 171, 2010.

5. MAJUSTE, K. \& GUEDES, M. V. Business Intelligence: vantagem competitiva.
Techoje. Disponivel em: < http://www.techoje.com.br/site/techoje/ca tegoria/detalhe_artigo/532>.

6. MÜLLER, R. M.; LINDERS, S.; PIRES, L. F. Business Intelligence and Serviceoriented Architecture: A Delphi Study. Information Systems Management, v. 27, p. 168-187, 9 abr 2010.

7. OLIVEIRA, F. B. Tecnologia da informação e da comunicação: Desafios e propostas estratégicas para $\mathrm{O}$ desenvolvimento dos negócios. São Paulo: Pearson Prentice Hall: Fundacão Getúlio Vargas, 2006.

8. PALMISANO, A.; ROSINI, A. M. Administração de Sistemas de Informação e a Gestão do Conhecimento. São Paulo: Thomson, 2003.

9. PRIMAK, Fabio Vinicius. Decisões com B.I. - Business Intelligence. São Paulo: Ciencia Moderna, 2008.

10. SABHERWAL, R.; BECERRAFERNANDEZ, I. Business Intelligence. Hoboken, NJ: John Wiley \& Sons, 2009. 